\title{
A VISITAÇÃO VIRTUAL NO CONTEXTO DO AMBIENTE PRISIONAL E O ATENDIMENTO AO PRINCÍPIO DO MELHOR INTERESSE DE CRIANÇAS E ADOLESCENTES
}

\author{
VIRTUAL VISITATION IN THE CONTEXT OF THE PRISON ENVIRONMENT AND ATTENDING \\ THE PRINCIPLE OF THE BEST INTEREST OF CHILDREN AND ADOLESCENTS
}

Livia Severo do Valle

Graduada em Comunicação Social pela Universidade Federal do Espirito Santo (UFES) Graduada em Direito pela Faculdade Espirito Santense de Ciências Jurídicas - PIO XII Pós-graduação lato sensu - MBA Profissional em Marketing Servidora Pública Municipal Advogada livia.svalle@gmail.com

\section{RESUMO}

Este artigo se propõe a discutir se a implantação da visitação virtual em ambiente prisional seria uma alternativa viável para promover e fortalecer os laços de afetividade entre pais presos e seus respectivos filhos, e com isso, contribuir para a promoção e o atendimento do princípio do melhor interesse da criança e do adolescente, minorando desta forma as possibilidades de ocorrência de abandono afetivo e a alienação parental. $\mathrm{O}$ trabalho tem como referência espacial o complexo penitenciário de Xuri, localizado em Vila Velha/ ES. Como objeto sociológico e jurídico se percebe a atenção crescente aos interesses das crianças e adolescentes por parte do ordenamento jurídico brasileiro. Entrecruzando este cenário tem-se o desenvolvimento atual das redes sociais e o engajamento ativo da quase totalidade da população brasileira nessas novas tecnologias. Sua abordagem busca, inicialmente, debater a questáo jurídica do melhor interesse das crianças e adolescentes para entâo mergulhar no ambiente prisional e suas debilidades e daí segue para discutir o cenário das mídias sociais que conduz à conclusão de que o estabelecimento de visitaçôes virtuais no ambiente prisional mostra-se sim como medida viável capaz de trazer praticidade, comodidade, segurança e aprofundamento de laços garantindo o direito de convivência familiar e o princípio do melhor interesse do menor.

Palavras-chave: Direito de Família. Princípio do Melhor Interesse. Alienação parental. Sistema prisional. Visitação virtual.

\section{ABSTRACT}

This article aims to discuss whether the implementation of virtual visitation in a prison environment would be a viable alternative to promote and strengthen the bonds of affection between imprisoned parents and their respective children, and thus contribute to the 
promotion and care of the principle of the best interest of children and adolescents, thus reducing the possibilities of occurrence of affective abandonment and parental alienation. The work has as spatial reference the penitentiary complex of Xuri, located in Vila Velha/ ES. As a sociological and legal object, there is increasing attention to the interests of children and adolescents by the Brazilian legal system. Crossing this scenario is the current development of social networks and the active engagement of almost all of the Brazilian population in these new technologies. His approach seeks, initially, to debate the legal issue of the best interest of children and adolescents and then immerse themselves in the prison environment and its weaknesses and then proceeds to discuss the scenario of social media that leads to the conclusion that the establishment of virtual visits in the prison environment is rather a viable measure capable of bringing practicality, convenience, security and deepening of ties ensuring the right of family coexistence and the principle of the best interest of the minor.

Keywords: Family law. Principle of best interest. Parental alienation. Prison system. Virtual visitation.

Data de submissão: 09/07/2020

Data de aceitação: 05/10/2020

\section{SUMÁRIO}

INTRODUÇÃO 1. O PRINCÍPIO DO MELHOR INTERESSE DE CRIANÇAS E ADOLESCENTES. 1.1 Do Direito à Convivência Familiar 1.2 A Alienação Parental e o Abandono Afetivo 2. O AMBIENTE PRISIONAL E SUA INFLUÊNCIA NO UNIVERSO FAMILIAR 2.1 O Poder Familiar 2.2 O Estigma do Presidiário 3 MÍDIAS SOCIAIS E A SUA PRESENÇA NO PODER JUDICIÁRIO 4. A VISITAÇÃO VIRTUAL COMO COMPLEMENTO AO CONVÍVIO FAMILIAR 4.1 A Visita no Sistema Prisional Capixaba e a Viabilidade da Visitação Virtual: Uma Análise do Atendimento do Princípio do Melhor Interesse da Criança e do Adolescente CONSIDERAÇÓEES FINAIS

\section{INTRODUÇÁO}

Atualmente, muito se discute no Direito de Família sobre o Princípio do melhor interesse de crianças e adolescentes que, de acordo com a doutrina e o ordenamento jurídico moderno, apresenta status de absoluta prioridade. Tendo como referência a legislação, a doutrina e o próprio cenário de ampliação do acesso às redes sociais, o trabalho busca analisar se pode a visitação virtual contribuir para o atendimento do princípio do melhor interesse de crianças e adolescentes e com isso auxiliar a promoção de laços de afetividade entre pais e filhos que estão afastados do convívio pessoal diário devido ao cumprimento de pena de prisão, contribuindo assim para evitar condutas nocivas, dentre elas o abandono afetivo e a alienação parental, o que será abordado na primeira seção desse trabalho.

Na segunda seção será abordado o ambiente prisional e o estigma carregado pelo pre- 
so, bem como sua influência sobre o relacionamento intrafamiliar. Nesse contexto, o conceito sociológico de estigma, que possui Erving Goffman como um de seus maiores expoentes, foi empregado, a fim de compreender a figura do presidiário e os reflexos de tal imputação para o exercício do poder familiar.

$\mathrm{Na}$ terceira seção será brevemente apresentado o crescente papel das redes sociais no cotidiano do Poder Judiciário. Na quarta seção foi discutido o possível reflexo sobre eventual aplicação da chamada visitação virtual, a qual será questionada enquanto meio capaz, ou não, de aproximação e fortalecimento de laços afetivos entre familiares, bem como sua viabilidade. Nesse cenário, é de grande relevância social e jurídica abrir discussão sobre a prática da visitação virtual, a fim de averiguar se a mesma pode ser capaz de minorar a distância emocional/afetiva existente entre pais e filhos afastados do convívio pelo sistema prisional.

A pesquisa eletrônica mostrou-se significativamente necessária, buscando-se informaçóes pertinentes ao tema, as quais foram encontradas em endereços eletrônicos como jornais e artigos sobre a aplicabilidade da Internet e novas tecnologias, enquanto instrumentos a serem empregados no cotidiano do Poder Judiciário, em especial no que se refere a visitação virtual, visto esta temática ainda carecer de produçóes acadêmicas dispostas a discuti-la.

Neste trabalho foi empregada a pesquisa exploratória com o fito de proporcionar maior proximidade com o problema, com vistas a torná-lo mais explícito e contribuir com a construção de hipóteses ${ }^{1}$, como ensina as boas referências da área metodológica ${ }^{2}$. As técnicas de coleta de dados empregadas no trabalho em questão foram a pesquisa bibliográfica, documental, eletrônica e um questionário enviado e respondido pela Secretaria de Estado da Justiça do Espírito Santo (SEJUS-ES).

Para uma compreensão holística e a interconexão daquilo que resultou nas seções 1,2 e 3 foi adotada a pesquisa bibliográfica a qual se deu a partir do levantamento de referências teóricas que pudessem permitir o aprofundamento das questóes envolvendo o melhor interesse das crianças e adolescentes, o ambiente prisional e as mídias sociais.

Feita a discussão, buscou-se na seção 4, por meio da pesquisa qualitativa, compreender o cenário de visitação às unidades prisionais tendo como objeto de estudo o Complexo Penitenciário de Xuri, localizado na região rural do município Vila Velha-ES que, devido à distância e tamanho do complexo, implica em consideráveis dificuldades de deslocamento físico da população mais carente para as visitações, em especial de crianças. Nesse aspecto, o deslocamento para a visitação aos presídios do complexo pelos familiares também foi observado por meio de ida da pesquisadora ao complexo penitenciário para realizar observação não participante.

Os dados referentes aos procedimentos institucionalizados aos quais os familiares são submetidos para terem acesso à visitação aos seus parentes presos, bem como os proce-

1 GERHARDT, Tatiana Engel; SILVEIRA, Denise Tolfo. Métodos de Pesquisa. 2009. Disponível em:<http://meiradarocha.jor.br/news/tcc/files/2017/12/Gerhardt-e-Silveira.-M\%C3\%A9todos-de-PesquisaEAD-UFRGS.pdf>. Acesso em: 16 set. 2020.

2 GIL, Antônio Carlos. Como elaborar projetos de pesquisa, 2002. 
dimentos executados por parte dos agentes estatais nos processos de acompanhamento, revista, tempo de visitação etc., foram levantados, via questionário, remetido diretamente a Secretaria de Estado da Justiça do Espírito Santo (SEJUS-ES), tendo sido recebido com as respostas que permitiram ter uma visão mais ampla do cenário.

\section{O PRINCÍPIO DO MELHOR INTERESSE DE CRIANÇAS E ADOLESCENTES}

A Constituição da República Federativa do Brasil de 1988, conhecida por seu viés social, promoveu diversas mudanças na compreensão de esferas significativas da sociedade, inclusive no âmbito das relaçôes familiares. Sobre a questão, ROSA $^{3}$ esclarece que:

O conceito de família, até então extremamente taxativo, passou a apresentar um conceito plural. As mudanças foram tão paradigmáticas que, tal como um divisor de águas, podemos dividir o Direito de Família em antes e depois do advento da Constituição Federal.

Nesse contexto, a proteção do bem-estar de crianças e adolescentes encontrou o reforço necessário em nosso ordenamento, pois atualmente apresenta status de "absoluta prioridade”, de acordo com o art. $227^{4}$ da Constituição Federal de 1988. E, em consonância com o texto constitucional, a Lei $\mathrm{n}^{\circ}$ 8.069/1990 (Estatuto da Criança e do Adolescente - ECA) adota a chamada "proteção integral" específicos dos mais jovens.

A doutrina da proteção integral e o princípio do melhor interesse aqui discutidos são "duas regras basilares do direito da infância e da juventude que devem permear todo tipo de interpretação dos casos envolvendo crianças e adolescentes. Trata-se da admissão da prioridade absoluta dos direitos da criança e adolescente" ${ }^{3}$. Nesse sentido, o princípio do melhor interesse seria "a representação do princípio da dignidade humana aplicada à criança e ao adolescente" 7 .

De forma ilustrativa, destacam-se quatro vieses do princípio do melhor interesse, ilustrados como "orientação do Estado-legislador, orientação ao Estado-juiz, orientação ao Estado-administrador e como orientação à família”:

(1) orientação do Estado-legislador: a lei deve prever a melhor consequência para a criança ou adolescente [...]; (2) orientação ao Estado-juiz: o magistrado moderno da infância e da juventude deve

\footnotetext{
3 ROSA, Conrado Paulino da. Curso de direito de família contemporâneo, 2016, p. 36.

4 Art. 227. É dever da família, da sociedade e do Estado assegurar à criança, ao adolescente e ao jovem, com absoluta prioridade, o direito à vida, à saúde, à alimentação, à educação, ao lazer, à profissionalização, à cultura, à dignidade, ao respeito, à liberdade e à convivência familiar e comunitária, além de colocá-los a salvo de toda forma de negligência, discriminaçáo, exploração, violência, crueldade e opressáo.

5 Art. $1^{\circ}$ Esta Lei dispóe sobre a proteção integral à criança e ao adolescente.

6 ISHIDA, Valter Kenji. Estatuto da Criança e do Adolescente: doutrina e jurisprudência, 2015, p. 2.

7 MONACO, 2005, p.179, apud ISHIDA, 2015, p.3.
} 
fornecer uma aplicação da lei ao caso concreto de acordo com as reais necessidades da criança e do adolescente [...]; (3) orientação ao Estado-administrador: em sua atividade de manuseio de políticas públicas deve se balizar por este princípio [...] (4) orientação à família: a família natural ou extensa devem sempre sopesar os interesses e as ideias da criança e do adolescente ${ }^{8}$.

O princípio do melhor interesse configura o tratamento prioritário que crianças e adolescentes devem receber do Estado, da família e da sociedade. Dessa maneira, "esse princípio se aplica tanto nas situações de conflito, como em uma posição de determinação da guarda, quanto no cotidiano, como na escolha da melhor linha de educaçáo" ${ }^{\prime}$. Nesse contexto, o direito à convivência familiar se faz primordial, constituindo-se como uma das necessidades básicas de crianças e adolescentes.

\subsection{Do Direito à Convivência Familiar}

O direito à convivência familiar também está previsto no texto constitucional de 1988, em seu artigo 227. Ele se expressa como "a relação afetiva, diária e duradoura das pessoas que compóem a entidade familiar, sejam parentes ou não, no ambiente comum”. A convivência humana, de acordo com Madaleno ${ }^{10}$, se estrutura por meio "de cada uma das diversas células familiares que compóem a comunidade social e política do Estado, que assim se encarrega de amparar e aprimorar a família, como forma de fortalecer a sua própria instituição política". Nesse contexto, a família é vista como "o ninho no qual as pessoas se sentem recíproca e solidariamente acolhidas e protegidas, especialmente as crianças"11.

Segundo o Decreto no 99.710, de 21 de novembro de $1990^{12}$, que promulgou a Convenção sobre os Direitos da Criança, a convivência familiar se faz necessária, mesmo nos casos em que os pais se encontram geograficamente distantes, ou mesmo separados devido a uma medida adotada pelo próprio Estado, a menos que isso seja contrário ao interesse maior da criança ${ }^{13}$.

No que tange ao convívio familiar, as discussões relacionadas à afetividade se fazem cada

8 MONACO, 2005, p.181-183, apud ISHIDA, 2015, p.3-4.

9 MADALENO, Ana Carolina Carpes; MADALENO, Rolf. Síndrome da Alienaçáo Parental: importância da detecçáo - aspectos legais e processuais, 2018, p. 27.

10 MADALENO, Rolf. Direito de Família, 2018, p. 81.

11 MADALENO, Ana Carolina Carpes; MADALENO, Rolf. Síndrome da Alienaçáo Parental: importância da deteç̧áo - aspectos legais e processuais, 2018, p. 26.

12 BRASIL. Decreto no 99.710, de 21 de novembro de 1990. Convençáo sobre os Direitos da Criança. Portal da Legislaçáo Governo Federal.

13 Quando essa separação ocorrer em virtude de uma medida adotada por um Estado Parte, tal como detenção, prisão, exílio, deportação ou morte (inclusive falecimento decorrente de qualquer causa enquanto a pessoa estiver sob a custódia do Estado) de um dos pais da criança, ou de ambos, ou da própria criança, o Estado Parte, quando solicitado, proporcionará aos pais, à criança ou, se for o caso, a outro familiar, informaçóes básicas a respeito do paradeiro do familiar ou familiares ausentes, a náo ser que tal procedimento seja prejudicial ao bem-estar da criança. 
vez mais presentes em nosso ordenamento jurídico, tamanha a sua complexidade e importância. Nesse sentido, Tartuce ${ }^{14}$ esclarece que:

De toda sorte, deve ser esclarecido que o afeto equivale à interação entre as pessoas, e não necessariamente ao amor, que é apenas uma de suas facetas. $\mathrm{O}$ amor é o afeto positivo por excelência. Todavia, há também o ódio, que constitui o lado negativo dessa fonte de energia do Direito de Família Contemporâneo.

Afetividade e filiação solidificam-se com o necessário convívio familiar. A filiação não se trataria apenas de "um determinismo biológico, ainda que seja da natureza humana o impulso à procriação; todavia, ela emerge da construção cultural e afetiva permanente, que se faz na convivência e na responsabilidade" ${ }^{15}$. Nesse cenário, o direito à convivência familiar objetiva reforçar os laços de afetividade, a fim de que condutas nocivas como a alienação parental e o abandono afetivo não possam se desenvolver.

\subsection{A Alienação Parental e o Abandono Afetivo}

De tal maneira, o afeto nas relações faz-se tão vital quanto às necessidades mais básicas do ser humano, pois reflete a incansável busca do indivíduo por equilíbrio, a necessária aceitação perante o meio em que vive, e também, por felicidade. Em contraponto a tais anseios, práticas nocivas como a alienação parental e o abandono afetivo atuam em descompasso com os deveres de proteção e convivência devidamente expressos pelo ordenamento jurídico. Segundo Farias e Rosenvald ${ }^{16}$, a alienação parental foi regulamentada pela Lei $\mathrm{n}^{\circ} 12.318 / 10$ e diz respeito as interferências na formação psicológica dos menores conduzidas ou estimuladas geralmente por um dos pais, avós ou por terceiros que tenham o menor sob a sua autoridade, guarda ou vigilância, com o intuito de causar prejuízos ao vínculo afetivo existente o genitor e seu filho.

Para Pereira ${ }^{17}$, "a discussão do abandono afetivo transcende os seus aspectos jurídicos e éticos, para atingir uma dimensão política e social”, pois:

As milhares de crianças de rua e na rua estão diretamente relacionadas ao abandono paterno ou materno, e não apenas à omissão do Estado em suas políticas públicas. Se os pais fossem mais presentes na vida de seus filhos e não os abandonassem afetivamente, isto é, se efetivamente os criassem e educassem, cumprindo os princípios e regras jurídicas, não haveria tantas crianças e adolescentes com sintomas de desestruturação familiar.

Nesse sentido, a visualização de práticas de alienação parental exige alguns critérios de

TARTUCE, Flavio. Direito Civil: direito de família, 2017, p. 29.

15 TARTUCE, Flavio. Direito Civil: direito de família, 2017, p. 29.

16 FARIAS, Cristiano Chaves de; ROSENVALD, Nelson. Curso de Direito Civil, 2015, p. 105.

17 PEREIRA, Rodrigo da Cunha. Divórcio: teoria e prática, 2013, p.115. 
identificação do observador ${ }^{18}$ :

Um dos primeiros sintomas da instauraçáo completa da síndrome da alienação parental se dá quando o menor absorve a campanha do genitor alienante contra o outro e passa, ele próprio, a assumir o papel de atacar o pai alienado, com injúrias, depreciaçóes, agressóes, interrupçáo da convivência e toda a sorte de desaprovaçóes em relação ao alienado. Os menores passam a tratar seu progenitor como um estranho a quem devem odiar, se sentem ameaçados com sua presença, embora, intimamente, amem esse pai como o outro genitor. Para o pai alienado é um choque ver que seu próprio filho é quem lhe dirige as palavras de ódio antes escutadas do outro cônjuge, o que pode ocasionar, inclusive, diante da sensação de impotência, o seu afastamento da criança - exatamente como quis e planejou o alienador.

$\mathrm{O}$ art. 2º , parágrafo único, da Lei ${ }^{\circ}$ 12.318/2010 (Lei da Alienação Parental) traz diversas formas exemplificativas do que seria a alienação parental. Em comum tais apontamentos têm a postura de um dos genitores, ou mesmo dos dois em contraponto, com ou sem auxílio de terceiros que, no fundo, expressa um olhar unilateral sobre o que seria melhor para a criança, desconsiderando que a outra parte teria contribuiçóes positivas para a vida em desenvolvimento.

Segundo Pereira ${ }^{19}$, "as sequelas emocionais dos filhos são sempre gravíssimas e, na maioria dos casos, irreversíveis". E, por fim, o mesmo complementa que "a violação das normas constitucionais pelo alienador é flagrante: princípio do melhor interesse da criança, princípio da dignidade humana e princípio da paternidade responsável.”

Nesse contexto é importante a análise quanto ao recluso, posto que a distância imposta pelo cumprimento da pena de prisão mostra-se como um potencial facilitador de tais práticas nocivas, pois sua convivência com o menor já está comprometida, ainda mais se alinhada com sentimentos de rancor, preconceito ou desprezo, incutidos por um possível genitor alienador, ou por outros familiares presentes na criação (como avós, tios, dentre outros). E, por tudo isso, o desenvolvimento dessa relaçáo exige uma atenção especial da sociedade, da própria família e também do Estado.

\section{O AMBIENTE PRISIONAL E SUA INFLUÊNCIA NO UNIVERSO FAMILIAR}

\subsection{O Poder Familiar}

Regra geral, o poder familiar é um direito-dever de ambos os pais, de participar e estar presente na vida de seus filhos, sobretudo em nome do melhor interesse do menor. Em

\footnotetext{
18 MADALENO, Ana Carolina Carpes; MADALENO, Rolf. Síndrome da Alienaçáo Parental: importância da deteç̧áo - aspectos legais e processuais, 2018, p. 43.

19 PEREIRA, Rodrigo da Cunha. Divórcio: teoria e prática, 2013, p.98.
} 
relação à questão ${ }^{20}$ :

"O poder familiar é irrenunciável, intransferível, inalienável e imprescritível, pertencente a ambos os pais, do nascimento aos 18 anos, ou com a emancipação de seus filhos. Em caso de discordância, é assegurado o direito de recorrer à Justiça. Mesmo quando os pais são separados, o não detentor da guarda continua titular do poder familiar, que pode apenas variar de grau quanto a seu exercício, não quanto à sua titularidade".

Indo além, o direito de visitas pode ser instituído inclusive quando o genitor não guardiāo "for viciado em tóxicos, alcoólatra inveterado ou psicopata, porém restringido a um local adequado, determinado em juízo e com o acompanhamento de terceira pessoa, a visitação assistida." ${ }^{1}$

No entanto, certos critérios relacionados ao poder familiar foram pontuados pelo Estatuto da Criança e do Adolescente, a fim de resguardar o melhor interesse do menor. O direito a convivência com o genitor privado de liberdade, por exemplo, está assegurado pelo Estatuto, segundo o art. $19, \$ 4^{022}$. Assim, é importante destacar que a condenação criminal nem sempre acarretará a perda do poder familiar do condenado em razão de seu filho menor. A legislação brasileira traz hipóteses em que haverá perda do poder familiar nessas circunstâncias e, nesse sentido a Lei ${ }^{\circ}$ 13.715, de 24 de setembro de 2018 promoveu alteraçóes no Código Penal (art. 92, II), no Estatuto da Criança e do Adolescente (art. 23, $\$ 2^{\circ}$ ) e no Código Civil (art. 1.638, parágrafo único), impondo àqueles que cometerem "crimes dolosos sujeitos à pena de reclusão cometidos contra outrem igualmente titular do mesmo poder familiar, contra filho, filha ou outro descendente ou contra tutelado ou curatelado" a perda do poder familiar. Além desses, o art. $23 . \$ 2^{\circ}$ traz a destituição do poder familiar para aqueles que sofram "[...] condenaçáo por crime doloso sujeito à pena de reclusão contra outrem igualmente titular do mesmo poder familiar ou contra filho, filha ou outro descendente".

Portanto, se no caso concreto a convivência se mostrar prejudicial ao desenvolvimento, ou se não for sadia, pode ser depreender que o melhor seria o afastamento do pai ou da mãe, ao menos por um determinado período de tempo, a fim de que o princípio do melhor interesse possa ser efetivamente aplicado. Verifica-se que a condição de presidiário, por si só, não acarretará a perda do direito de visita do filho ao condenado, visto nem sempre haver em desfavor deste a perda do poder familiar.

\footnotetext{
20 MADALENO, Ana Carolina Carpes; MADALENO, Rolf. Síndrome da Alienaçáo Parental: importância da detecção - aspectos legais e processuais, 2018, p. 28.

21 MADALENO, Ana Carolina Carpes; MADALENO, Rolf. Síndrome da Alienaçáo Parental: importância da detecçáo - aspectos legais e processuais, 2018, p. 37.

$22 \$ 4^{\circ}$ Será garantida a convivência da criança e do adolescente com a mãe ou o pai privado de liberdade, por meio de visitas periódicas promovidas pelo responsável ou, nas hipóteses de acolhimento institucional, pela entidade responsável, independentemente de autorização judicial.
} 


\subsection{O Estigma do Presidiário}

Ao adentrar na esfera de discussão sobre o universo prisional, esbarra-se em um terreno arenoso, tamanha a diversidade de opinióes, especialmente sobre a figura do presidiário.

Segundo Goffman ${ }^{23}$, o termo estigma foi criado na Grécia, para se referir a "sinais corporais com os quais se procurava evidenciar alguma coisa de extraordinário ou mau sobre o status moral de quem os apresentava". Nesse sentido, "o estigma avisava a existência de um escravo, de um criminoso, de uma pessoa cujo contato deveria ser evitado". Em sua obra, foi empregado o termo "normal" para se referir a pessoas que atendem às expectativas sociais, físicas e morais básicas, aceitas de modo inconteste pela sociedade, e, referiu-se como "estigmatizadas" as pessoas que possuem um ou mais características ou comportamentos que divergem do que se espera. Tais expectativas, como podemos depreender da obra, seriam compartilhadas de forma intuitiva, interiorizada, fruto do senso comum. Ou seja, não se trata de algo plenamente consciente, mas sim enraizado social e culturalmente.

O autor ${ }^{24}$ menciona três tipos de estigmas nitidamente diferentes: as pessoas que possuem deficiências físicas e/ou mentais, os relacionados a raça, nação e religião, classificando os presidiários como os que possuem:

As culpas de caráter individual, percebidas como vontade fraca, paixôes tirânicas ou não naturais, crenças falsas e rígidas, desonestidade, sendo essas inferidas a partir de relatos conhecidos de, por exemplo, distúrbio mental, prisáo, vicio, alcoolismo, homossexualismo, desemprego, tentativas de suicídio e comportamento político radical (grifo nosso).

Em seu trabalho, Goffman considera que há um conjunto de indivíduos dos quais o estigmatizado pode esperar algum apoio (aqueles que compartilham seu estigma, que são definidos como seus iguais). Por exemplo, um grupo de presidiários "são definidos e se definem como seus iguais". Mas, além de seus "iguais", o autor também faz menção a um grupo de pessoas chamadas por ele de "informadas". O primeiro grupo de pessoas "informadas" são aquelas que estáo inseridas nas necessidades da pessoa que possui um estigma em particular (como as pessoas com deficiência) ou mesmo devido à sua atuação e dia a dia profissional (como os policiais, podendo tal constatação ser validamente estendida a outros profissionais, como agentes penitenciários, defensores públicos, membros do Ministério Público, historiadores, sociólogos, psicólogos, pesquisadores, dentre outros):

[...] a polícia, devido ao fato de ter que lidar constantemente com criminosos, pode se tornar "informada" em relação a eles, levando um profissional a declarar que "de fato os policiais são as únicas pessoas que, além de outros criminosos, o aceitam pelo que ele é”. 25

23 GOFFMAN, Erving. Estigma: notas sobre a manipulação da identidade deteriorada, 2008, p.11.

24 GOFFMAN, Erving. Estigma: notas sobre a manipulação da identidade deteriorada, 2008, p.14.

25 GOFFMAN, Erving. Estigma: notas sobre a manipulação da identidade deteriorada, 2008, p.39. 
O segundo tipo de pessoa "informada" refere-se "ao indivíduo que se relaciona com um indivíduo estigmatizado através da estrutura social - uma relação que leva a sociedade mais ampla a considerar ambos como uma só pessoa”. Dessa forma, para o autor: ${ }^{26}$

Assim, a mulher fiel do paciente mental, a filha do ex-presidiário, o pai do aleijado, o amigo do cego, a família do carrasco, todos estão obrigados a compartilhar um pouco o descrédito do estigmatizado com o qual eles se relacionam. Uma resposta a esse destino é abraçá-lo e viver dentro do mundo do familiar ou amigo do estigmatizado (grifo nosso).

Para Goffan ${ }^{27}$, "em geral, a tendência para a difusão de um estigma do indivíduo marcado para as suas relaçóes mais próximas explica por que tais relações tendem a ser evitadas ou a terminar, caso já existam". Indo além, exemplifica que muitos indivíduos não fazem a necessária diferenciação entre aquele que foi condenado à prisão e as pessoas que lhe são próximas, afirmando que "os problemas enfrentados por uma pessoa estigmatizada espalham-se em ondas de intensidade decrescente".

Martins ${ }^{28}$ aponta que "o preso é normalmente desacreditado devido seu comportamento desviante e, a criança por sustentar um vínculo estreito com o progenitor é contaminada pelo preconceito e pela sua condição de condenado". Indo além, também especifica as dificuldades enfrentadas pelos familiares ao apontar que $^{29}$ :

Ser familiar de encarcerados implica em compartilhar do mesmo estigma social que eles padecem. Muitas famílias não adquirem diante a sociedade local essa condição para não se tornarem passíveis de censuras, que os colocariam na mesma classe social do presidiário.

As pessoas classificadas como "informadas", seja por sua capacitação, seja pela convivência derivada do exercício profissional, possuem o condão de prestar apoio ao estigmatizado, no sentido de ampliarem o campo de visão daqueles que os ignoram, de forma a auxiliarem, dentro do possível, sua maior aceitabilidade frente a sociedade, buscando minorar o preconceito e apresentar uma nova perspectiva sobre sua situação. Indo além, o Estado, que possui o ônus de promover direitos e garantias ao indivíduo, deve estimular a necessária ressocialização do presidiário, onde a aproximaçáo familiar, mesmo que por meio virtual, mostra-se como um possível instrumento de desconstrução da figura do presidiário, ao menos para crianças e adolescentes, auxiliando que os mesmos cheguem as suas próprias conclusốes quanto a figura paterna/materna, por intermédio da ampliação da convivência.

O Estatuto da Criança e do Adolescente estabelece a obrigação estatal de prevenir ameaças

\footnotetext{
26 GOFFMAN, Erving. Estigma: notas sobre a manipulação da identidade deteriorada, 2008, p.39.

27 GOFFMAN, Erving. Estigma: notas sobre a manipulação da identidade deteriorada, 2008, p.39-40.

28 MARTINS, Verônica Pinheiro. A percepçáo das crianças sobre o pai presidiário, segundo a técnica desenho da família. 2016.

29 KOMINSKY; PINTO; MIYASHIRO, 2005, apud MARTINS, 2016 [s.p.]. Disponível em: <https:// psicologado.com.br/atuacao/psicologia-juridica/a-percepcao-das-criancas-sobre-o-pai-presidiario-segundo-atecnica-desenho-da-familia>. Acesso em: 04 out. 2018.
} 
à integridade física ou psíquica dos menores ${ }^{30}$. Assim, surge o questionamento a respeito da convivência de crianças e adolescentes com pais infratores, onde se indaga até que ponto tal contato seria saudável ou mesmo necessário. A reflexão sobre o assunto exige razoabilidade e especialmente bom senso, não existindo respostas prontas para a questão, devendo cada caso ser analisado de acordo com as particularidades que apresentar.

\section{MÍDIAS SOCIAIS NO PODER JUDICIÁRIO}

A prática de videoconferências e intimaçóes eletrônicas mostra-se presente no Poder Judiciário de muitas regióes do país, além da troca de mensagens por smartphones para fins processuais. Cabe acrescentar que a abertura e acompanhamento de processos somente por meios eletrônicos já sáo uma realidade em via de implantação no Estado do Espírito Santo, onde juízes, promotores, defensores e advogados que atuam na execuçáo penal passaram a ter acesso, via Internet, às Guias de Execução Penal que, como ocorre em outras Unidades Federativas, como Paraná, por exemplo, tramitam via Sistema Eletrônico de Execução Unificada - SEEU, cuja digitalização objetivou trazer agilidade, redução de custos, dentre outras finalidades.

Segundo matéria publicada no site Gazeta Online ${ }^{31}$, o aplicativo de troca de mensagens WhatsApp está sendo utilizado como ferramenta para juízes do Estado do Espírito Santo para agilizar intimaçóes. O caso exposto versava sobre processo da Vara da Família de Cariacica-ES, que utilizou o WhatsApp para intimar a parte sobre uma decisão judicial ${ }^{32}$.

Em outra ocasião, o Ministério Público do Estado do Espírito Santo (MPES), por meio da Promotoria de Justiça de Guarapari-ES, utilizou o aplicativo WhatsApp para viabilizar uma audiência, visto que uma das partes já não morava no Espírito Santo. O julgamento

30 Art. 17. O direito ao respeito consiste na inviolabilidade da integridade física, psíquica e moral da criança e do adolescente, abrangendo a preservação da imagem, da identidade, da autonomia, dos valores, ideias e crenças, dos espaços e objetos pessoais.

Art. 18. É dever de todos velar pela dignidade da criança e do adolescente, pondo-os a salvo de qualquer tratamento desumano, violento, aterrorizante, vexatório ou constrangedor.

31 GAZETA ONLINE. Justiça usa tecnologia para agilizar audiência e finalizar processos. 2017.

32 "O juiz deferiu uma liminar obrigando a parte a permitir que a filha passasse as férias com o pai. No entanto, a mãe da menina continuou o impedindo de ver a filha [...]. A advogada entrou com uma ação pedindo a aplicação de multa caso a decisão continuasse sendo descumprida. Entretanto, o oficial de Justiça foi até a residência da mulher indicada no processo, mas ela mudou de endereço na noite anterior [...]. A advogada peticionou em janeiro, alegando que ela havia se mudado para não ser intimada. $\mathrm{O}$ pedido foi fundamentado com a lei que autoriza a intimação por meio eletrônico. Foi cumprido o despacho, e a intimação ocorreu em 20 de janeiro. A parte (ex-mulher do cliente) leu a intimaçáo enviada pelo WhatsApp e compareceu ao gabinete do juiz no dia seguinte, cumprindo a decisão”. 
ocorreu na $3^{\text {a }}$ Vara Criminal de Guarapari-ES. ${ }^{33}$

As novas ferramentas de comunicação também estão presentes na seara do Direito Processual Penal, para prever a possibilidade de realização de interrogatório e outros atos processuais por sistema de videoconferência. A Lei no $11.900 / 2009$ promoveu mudanças no Código Processo Penal ao dispor que:

Art. 185. $\$ 2$ o Excepcionalmente, o juiz, por decisão fundamentada, de ofício ou a requerimento das partes, poderá realizar o interrogatório do réu preso por sistema de videoconferência ou outro recurso tecnológico de transmissão de sons e imagens em tempo real, desde que a medida seja necessária para atender a uma das seguintes finalidades:

I - prevenir risco à segurança pública, quando exista fundada suspeita de que o preso integre organizaçáo criminosa ou de que, por outra razão possa fugir durante o deslocamento;

II - viabilizar a participação do réu no referido ato processual, quando haja relevante dificuldade para seu comparecimento em juízo, por enfermidade ou outra circunstância pessoal;

III - impedir a influência do réu no ânimo de testemunha ou da vítima, desde que não seja possível colher o depoimento destas por videoconferência, nos termos do art. 217 deste Código;

IV - responder à gravíssima questão de ordem pública.

Para Galvão ${ }^{34}$, "é certo que o contato entre o preso e seu defensor e entre o preso e o magistrado é diminuído quando o recurso tecnológico é utilizado para qualquer ato processual". As diferenças entre o contato virtual e o físico não estão sendo ignoradas pela Lei ${ }^{\circ}$ $11.900 / 09$, pois, caso fossem idênticos, não haveria "razáo para o legislador, a doutrina e a jurisprudência reafirmarem a excepcionalidade do interrogatório judicial à distância ou para se preocuparem com a bilateralidade e qualidade da transmissão dos sons e imagens".

Segundo dados divulgados pelo Governo do Estado do Espírito Santo, o gasto com o deslocamento de presos para as audiências de custódia é de quinze milhóes de reais por ano. Os custos foram publicizados durante a transmissão de um teleaudiência experimental realizada em agosto de 2020, no gabinete do governador Renato Casagrande, no Palácio

\footnotetext{
33 Entrevista concedida pelo promotor criminal Fábio Langa ao jornal Gazeta Online, no ano de 2017. "A vítima que foi à audiência informou que a farmacêutica havia se mudado para o Rio de Janeiro. O trâmite para convocá-la a depor seria burocrático e precisaria de outra audiência. Por isso, fizemos a oitiva (ouvir em Juízo) pelo WhatsApp mesmo, através de vídeo" [...]. "A farmacêutica respondeu a perguntas da juíza para garantir sua identidade. Outros recursos já foram usados para localizar vítimas e testemunhas, como redes sociais e o próprio telefone".
}

34 GALVÃO, Danyelle da Silva. É válido realizar a audiência de custódia por videoconferência? 2016. 
Anchieta, em Vitória-ES ${ }^{35}$.

Pelo exposto, depreende-se que as novas tecnologias estáo presentes no cotidiano do Poder Judiciário do Espírito Santo, comprovando seu aspecto prático e crescente importância.

\section{A VISITAÇÃO VIRTUAL COMO COMPLEMENTO AO CONVÍVIO FAMILIAR}

Atualmente, indaga-se de que maneira a Internet pode interferir no universo do Direito de Família, visto sua crescente presença no cotidiano dos mais diversos lares do país:

[...] hoje é quase impossível viver sem Internet, abriram-se várias possibilidades de mudanças tanto estrutural como ambiental, a conexão está presente em todas as açôes, na prática e no convívio social e familiar, encontrando espaço em todas as situaçóes, mesmo as mais adversas, pois permite que a comunicação seja instantânea e as informaçóes sejam rápidas e de fácil acesso. Vive-se a era da informação, da tecnologia, da pós-modernidade, assim o ser humano é construtor desta história e como tal tem responsabilidade pelos atos e pelas atitudes, não esquecendo que em todo espaço, em todo ambiente é necessário equilíbrio, pois à medida que se constrói, se busca reformular e (re) significar valores éticos, morais e sociais ${ }^{36}$.

Em tal contexto, as visitas virtuais são entendidas como interações que ocorrem de forma online, por meio de celulares ou computadores equipados com webcams e plataformas como Skype, Facetime, Zoom, Telegram, dentre outros:

Uma exploração do contato pai-filho virtual é oportuna desde que a tecnologia moderna está criando um novo mundo de comunicaçóes sociais, especialmente para jovens cujo uso de mensagens de texto, e-mail, sites, webcams e salas de bate-papo está explodindo em todo o mundo ${ }^{37}$.

Nesse sentido, a prática da visitação virtual mostra-se uma alternativa, no que diz respeito ao estabelecimento de laços de afetividade familiar, especialmente entre pais e filhos. Segundo Gomes ${ }^{38}$, “a visita virtual é defendida em vários outros países e seria mais uma

\footnotetext{
35 A teleaudiência foi realizada pela 4a Vara Criminal de Vitória-ES, e contou com participação dos réus, que permaneceram no Centro de Detenção Provisória de Viana II (CDPV II), acompanhados de seus advogados. O Governo destacou que a adoção das teleaudiências trará agilidade aos processos e economia para o Estado. A medida também pode reduzir a superlotação e assim resultar em uma economia ainda maior, uma vez que o custo médio de um detento hoje é de R \$1.600,00 (mil e seiscentos reais) por mês. Disponível em: <https:// tribunaonline.com.br/visitas-virtuais-a-presos-pelo-celular>. Acesso em: 17 set. 2020.

36 AMARAL, Érico Marcelo Hoff do; KÖHLER, Jussara Farias. A Influência da Internet nas relaçóes familiares. Repositório Digital da Universidade Federal de Santa Maria - UFSM. 2010, p. 9.

37 BARNES, Jessica; POLAK, Shely; MISHNA, Faye; SAINI, Michael. Parenting Online: An Exploration of Virtual Parenting Time in the Context of Separation and Divorce, Journal of Child Custody. 2013, p. 121.

38 GOMES, Marcus Vinícius da Silva; SILVA, Antônio Dantas da Silva; TEIXEIRA FILHO, Fernando Robério Passos. Internet e as transformaçóes no direito das famílias. 2014.
} 
maneira do pai ou mãe que não possui a guarda, conseguir manter o contato com o filho." Tanto que, a visitação virtual já mostra-se presente nas decisões judiciais como forma incentivada de manutenção de contato e fortalecimento de vínculos entre pais e filhos afastados geograficamente. Em tal contexto, o IBDFAM ${ }^{39}$, expôs seu viés prático, ao retratar a decisão da ministra Nancy Andrighi, no REsp 1.251.000/MG (2011/0084897-5):

[...] a guarda compartilhada física (custódia física conjunta) é o ideal a ser buscado no estabelecimento da guarda, sujeita, contudo, às peculiaridades fáticas que envolvem pais e filhos, mas jamais sob o fundamento da distância entre as moradias dos pais, questão hoje minorada por diversos meios de comunicaçáo, de modo instantâneo pela rede mundial de computadores (internet, e-mail, vídeo de imagem e som, Skype, Google Talk, celulares permitindo que pessoas se vejam enquanto falam, Whats $A p p$ ), disponibilizados como 'visitas virtuais' ou 'encontros online'. Mesmo entre cidades ou países distantes pais e filhos podem manter uma adequada e frequente comunicação, assegurando presença contínua do pai na vida do filho, sem diminuição dos demais deveres que integram o rol dos atributos do poder familiar.

Baptista ${ }^{40}$ corrobora as vantagens presentes na "visitação virtual" ao defender que:

[...] traria pelo menos três benefícios para o menor. Um deles seria o de dificultar qualquer tipo de violência doméstica, inclusive o abuso sexual. As estatísticas revelam que as infraçóes contra os menores são muito mais frequentes no interior da família do que fora dela, e as comunicaçóes por vídeos de sons ou imagens inibiriam as açóes do infrator, podendo até mesmo fazer prova contra aqueles que de uma forma ou de outra agridem as crianças e adolescentes dentro dos lares. Outra vantagem seria a de atenuar os possíveis efeitos da alienação parental, nos casos em que um genitor - em geral aquele que mantém a guarda - procura impedir a presença do outro, obstruindo as visitas sob falsos argumentos. Mas sem dúvida o maior benefício que a visitaçáo virtual poderia trazer seria o de promover um contato mais frequente do filho com o genitor não guardião, principalmente em relação aos pais que moram em locais distantes das residências dos filhos, já que o objetivo maior do direito à visita é preservar os laços afetivos entre filhos de pais separados, muitas vezes abalados pelo rompimento do vínculo.

No polo oposto, possíveis entraves mostram-se presentes no que diz respeito à implantação da visitação virtual em todo o país. A título exemplificativo, Athayde ${ }^{41}$ destaca que um dos maiores desafios a serem enfrentados na modernização do Judiciário brasileiro "é a escassez de recursos da maioria da população do país, aliado à ojeriza que o computador provoca na maioria das pessoas, principalmente aos mais conservadores".

\footnotetext{
39 IBDFAM: Instituto Brasileiro de Direito de Família. STJ nega guarda compartilhada para pais que moram em cidades diferentes. 2016. .

40 BAPTISTA, Silvio. Direito de visita virtual. 2010.

${ }^{41}$ ATHAYDE, Aymir Ralin Pires. Informática e Justiça. 2010.
} 
Para Boechat ${ }^{42}$, no contexto das redes sociais digitais, o indivíduo que promove o contato "pode facilmente se livrar daquele que convocou à interação e daquele pelo qual foi convocado; pode, ainda, sentir-se próximo mesmo distante ou sentir-se distante mesmo estando próximo". Nesse contexto, ainda ressalta que:

As "relaçóes virtuais" encontram ressonância e se encaixam na liquidez da modernidade: fáceis de lidar, de entrar e sair, de compreender e de serem deletadas [...] Parece que a facilidade em desconectar-se, mais do que a de conectar-se, prossegue Bauman (2004), torna essas redes e seus dispositivos de entrada e saída populares e muito utilizados nas interaçôes humanas, afinal "estar conectado" mostra-se menos dispendioso, embora seja menos interessante para a criação e conservação de vínculos. Assim, enquanto a "proximidade topográfica" reclama por estabelecimento de laços, a "proximidade virtual" dissocia comunicação de relacionamento, segue definindo o padrão das demais proximidades e roubando a atenção para o desenvolvimento das habilidades que ela requer.

Diante dos dados apresentados, presume-se a viabilidade da aplicação da visitação virtual no contexto prisional capixaba. Mesmo diante da carência de uma legislação regulamentadora, decisões fundamentadas em prol da prática podem contribuir para a ampliação de tal medida, determinando-a de forma complementar a necessária visitação presencial, pois o que se visa é a ampliação do contato entre as partes, e não a substituição do contato presencial pelo virtual.

\subsection{A visita no sistema prisional capixaba e a viabilidade da visitaçáo virtual: uma análise do atendimento do princípio do melhor interesse da criança e do adolescente}

Nessa subseção pretende-se apresentar como atualmente funciona o processo de visitação às Unidades Prisionais (UPs) no Estado do Espírito Santo. As informaçóes aqui expressas foram elaboradas por meio de questionário e diretamente respondidas pela Gerência de Educação e Trabalho, integrante da Subsecretaria de Ressocialização, pertencente à Secretaria de Estado da Justiça, do Estado do Espírito Santo (SEJUS-ES), no mês de abril de 2019, objetivando averiguar como é o procedimento de visitação de crianças e adolescentes aos presídios capixabas, a fim de entender sua realidade e dinâmica. Dessa maneira, considerou-se a definição trazida pelo artigo $2^{\circ}$ da Lei $n^{\circ}$ 8.069/1990 (ECA) que estabelece como criança a pessoa até 12 anos de idade incompletos e adolescente aquele entre 12 e 18 anos de idade.

É importante ressaltar que em 2014 o ECA passou por modificações referentes à visitação de menores aos estabelecimentos prisionais, que foram trazidas pela Lei 12.962, de 08 de abril de 2014. Essas mudanças garantiram a possibilidade de visitas periódicas, que anteriormente dependiam de autorização judicial, independentemente da situação jurídica do preso.

\footnotetext{
42 BOECHAT, Ieda Tinoco. As famílias e as tecnologias digitais: a comunicação pela articulação de vieses
} não antes explorados. 1. ed. Curitiba: Appris, 2017, [s.p]. 
No que tange às UPs, cabe destacar que cada Estado pode estabelecer regramentos diferenciados em relação ao procedimento de visitação. No Estado do Espírito Santo, segundo informaçóes fornecidas pela Secretaria de Estado da Justiça (SEJUS-ES), a visitação é regulamentada pela Portaria 142 de 26 de fevereiro de 2010, em consonância com a Lei de Execução Penal (Lei no 7.210, de 11 de julho de 1984). De acordo com o quantitativo atualizado pela SEJUS-ES em 08 de maio de 2019, a população carcerária da Grande Vitória-ES representa 15.297 presos, entre homens e mulheres e 8.313 pertencentes ao interior do Estado, correspondendo a 23.610 pessoas o total geral.

No sistema prisional capixaba, a visita de crianças e adolescentes é permitida aos presos do regime fechado, semiaberto, presos provisórios e aos que estão cumprindo medida de segurança. Faz-se necessária a efetivação de um cadastro prévio para que a pessoa presa possa receber a visita de parente de primeiro grau (pai, mãe e filhos), de cônjuge ou companheiro (a), em dias determinados, desde que devidamente cadastrados. As pessoas que não constam no rol acima, permite-se o cadastro de parentes de segundo grau ou amigos, sendo limitado em duas credenciais, mediante comprovação documental e investigação social.

As visitas ocorrem, via de regra, aos finais de semana, dependendo da Unidade Prisional e do quantitativo de internos, aos sábados e domingos, ou apenas aos domingos, com periodicidade quinzenal. O tempo de duração da visita é de até 2 horas, em regra, não respondendo a SEJUS-ES sobre o horário em que as visitas efetivamente se iniciam. E, no que se refere ao limite de visitas por preso por dia de visitação e se em tal número são incluídos as crianças e adolescentes, informou que é seguida a Portaria 142 de 26 de fevereiro de 2010, em seu artigo $13, \$ 3^{\circ}$, com a ressalva de que em algumas unidades, mesmo a portaria limitando a quantidade de pessoas, "acaba-se liberando a entrada de todos os filhos" ${ }^{\text {" }}$. Nesse contexto, a visitação virtual demonstra sua relevância, pois tal período de contato poderia ser aumentado consideravelmente, tanto no período de duração, quanto na periodicidade, funcionando como um complemento à visita social. Além disso, as condiçóes de segurança seriam mantidas ou mesmo fortalecidas, visto que a visitação virtual não exigiria a presença física nas unidades prisionais, restando resguardado o interesse do menor e adolescente.

No que se refere ao procedimento de revista de segurança, a SEJUS-ES informou que o mesmo também é realizado em crianças e adolescentes, conforme estabelecido na Portaria 142 de 26 de fevereiro de $2010^{44}$ :

Art. $15 \$ 1^{\circ}$. O visitante será revistado por funcionário do mesmo sexo, que utilizará detector de metais, portal, banqueta de detecção de metais ou escâner de corpo;

$\$ 2^{\circ}$. A revista em menores de 12 anos realizar-se-á na presença dos pais ou responsáveis, observando-se o disposto no parágrafo anterior.

\footnotetext{
43 Art. $13 \$ 3^{\circ}$. As visitas serão limitadas ao número de dois visitantes maiores e um menor de 18 dezoito anos, por dia de visita, preservando as condiçóes de segurança na unidade prisional.

44 ESPÍRITO SANTO (Estado). Portaria no 142, de 26 de fevereiro de 2010. Regulamento Interno dos Centros de Detençáo Provisória. Diário Oficial dos Poderes do Estado do Espírito Santo, 2010. Disponível em: < https://sejus.es.gov.br/Media/sejus/Legisla\%C3\%A7\%C3\%A3o/Portarias/Portaria\%20n\%C2\%BA\%20 1582_Cadastramento\%20de\%20filhos\%20de\%20presos.pdf>. Acesso em: 09 maio 2019.
} 
Questionada se existe alguma forma de diferenciação (no que se refere ao procedimento ou local diferenciado) entre a visitação de menores e adultos, a SEJUS-ES informou que não, alegando que as visitas comuns "são realizadas em local próprio, em condiçóes dignas e que possibilitem a vigilância pelo corpo de segurança”.

Por fim, a SEJUS-ES afirmou que uma nova portaria de visita social "está em fase final de confecção, objetivando atualização e complementação da Portaria em vigor, tendo em vista que a mesma é de 2010, estando em alguns pontos obsoleta e/ou incompleta, de forma que retrate, na totalidade e de forma fidedigna, a atual realidade desta Secretaria”.

Nesse contexto, a Portaria no $1.582-S 08$ de outubro de $2014^{45}$ (SEJUS-ES), define medidas consoantes com as definidas pelo Estatuto da Criança e do Adolescente, no sentido de aproximação entre pais e filhos afastados pelo cumprimento de pena:

Art. $1^{\circ}$ Determinar à direção das Unidades Prisionais do Estado do Espírito Santo a adoçáo das medidas necessárias visando o cadastramento dos filhos das pessoas privadas de liberdade e a identificação de quem as acolhe, mesmo aqueles que não têm medida judicial de guarda provisória ou definitiva, mediante preenchimento de formulário próprio constante no Anexo Único desta portaria.

Art. $3^{\circ}$ Determinar que a pessoa privada de liberdade poderá indicar outra pessoa como responsável para levar seus filhos à Unidade prisional para visitá-lo, na hipótese de impossibilidade ou dificuldade de relacionamento com o pai ou a máe de seus filhos.

$\$ 1^{\circ}$. Caso a pessoa privada de liberdade não saiba quem é responsável pelos seus filhos, deverá repassar ao serviço social da Unidade Prisional as informaçóes que tiver para que sejam realizadas diligências visando a identificação e cadastro do mesmo.

Art. $5^{\circ}$ Sempre que for possível, a pessoa privada de liberdade deve ser alocada em Unidade Prisional mais próxima do endereço de seus filhos, visando preservar e garantir o convívio entre eles.

Sobre a específica indagação sobre a relevância da visitação virtual, como meio para a ampliaçáo de contato, a Portaria no $1.582-S$ apresenta elementos significativos para a sua possível implantaçáo, vista como uma forma complementar de aproximaçáo ao contato pessoal:

Art. $6^{\circ}$ Os filhos da pessoa privada de liberdade somente serão autorizados a adentrar à área de visita social acompanhados do responsável indicado e não serão constrangidos a ali permanecer, caso não se sintam à vontade para realizar ou prosseguir com a visita.

Art. $7^{\circ}$ A direção de Centros de Detenção Provisória deverá estipular dias e horários especiais para que as pessoas privadas de liberdade neles recolhidos possam receber visita de seus filhos.

$\$ 1^{\circ}$ Nas datas comemorativas representadas pelo Dia das Mães, Dia dos Pais, Dia das Crianças, a direção dos CDPs deverá propiciar

45 ESPÍRITO SANTO (Estado). Portaria no 1.582-S 08 de outubro de 2014. 
visitas que permitam o contato físico entre as pessoas privadas de liberdade e seus filhos.

\$2 Ficará a critério da direçáo dos CDPs, considerando-se a capacidade operacional da unidade, estabelecer outras datas onde ocorra visitação com contato físico entre as pessoas privadas de liberdade e seus filhos.

Por fim, a Resolução no 04, de 15 de julho de 2009, do Conselho Nacional de Política Criminal e Penitenciária - $\mathrm{CNPCP}^{46}$, vinculado ao Ministério da Justiça, defende, em seu artigo $8^{\circ}$ que, "a visita de familiares e pais presos deve ser estimulada visando à preservação do vínculo familiar e do reconhecimento de outros personagens do círculo de relacionamento parental”.

Nesse cenário, observa-se que o contato do menor com o genitor presidiário se mostra estimulada pela Administração Pública, por meio do procedimento de visitação periódica, de acordo com os dados e informaçóes aqui levantados. Nesse sentido, a visitação virtual demonstra ser uma opção a mais, a fim de trazer maior aproximação e praticidade para os indivíduos que fazem parte dessa realidade, resguardando o interesse da criança e do adolescente.

Fatores como os custos com o deslocamento, os compromissos profissionais e sociais do responsável pelo menor, condiçóes de saúde, mobilidade e financeiras, podem ser apontados como causas que ocasionam a redução ou mesmo a inviabilidade da visitação presencial. O Complexo Penitenciário de Xuri, localizado em Vila Velha-ES, ilustra, na prática, as dificuldades a serem contornadas, em especial pelas pessoas mais carentes. O complexo reúne o Centro de Detenção Provisória de Vila Velha (CDPVV), as Penitenciárias Estaduais de Vila Velha I, II, III e V, e a Semiaberta. Segundo dados divulgados pela SEJUS-ES, o complexo penitenciário de Xuri enfrenta superlotação. Com capacidade para 3.626 (três mil seiscentos e vinte e seis) internos, abrigou, em Julho de 2019, 7.892 (sete mil oitocentos e noventa e dois), chegando a uma superlotação de $117 \%{ }^{47}$. O complexo é conhecido por sua grande extensão e, por meio de observação náo participante, pode-se apontar que o local em que o complexo se localiza é um possível limitador da quantidade de visitas presenciais. Trata-se de um complexo localizado especificamente na BR-101 (rodovia federal), sem acostamento, com iluminação precária e estrada de terra batida, havendo empecilhos ainda maiores em dias de chuva, mostrando-se como dificultador de uma visitação periódica com menores, mesmo havendo linhas de ônibus voltadas para o local. A ala em que o preso está localizado também determina o quão distante o deslocamento físico será.

Indo além, outros aspectos devem ser levados em consideração no que tange à aplicabilidade da visitação virtual, que são os relacionados: a segurança da própria unidade prisional, que necessita fazer o controle de sua população, incluindo a entrada e saída de visitantes; o maior controle sobre a entrada de entorpecentes, que em várias situaçóes se dão nos

\footnotetext{
46 BRASIL. Ministério da Justiça e Segurança Pública. Conselho Nacional de Política Criminal e Penitenciária. Resolução no 04, de 15 de julho de 2009.

47 GAZETA ONLINE. Superlotação em Presídios do Complexo de Xuri está em 117\%. 2019.
} 
momentos de visita; o deslocamento de um interno para outra unidade prisional ainda mais distante da residência dos familiares, devido a brigas entre facçóes rivais, havendo a necessidade de transferência para uma região mais remota; por superlotação, obrigando a transferência de presos para outras regióes, impactando na logística de familiares quanto as visitas presenciais; familiares e amigos que mudam-se para outros Estados, perdendo a interação com o presidiário, dentre muitos outros aspectos.

\section{CONSIDERAÇÓES FINAIS}

Este trabalho buscou demonstrar que o princípio do melhor interesse faz-se presente em nosso ordenamento jurídico e de variadas formas, mas sempre objetivando o bem-estar de crianças e adolescentes. Apontou ainda que o Código Civil assegura o pleno exercício do poder familiar, além do dever de educação e guarda dos filhos, por ambos os pais. Discutiu-se como as práticas nocivas como a alienação parental e o abandono afetivo trazem inegáveis malefícios no que diz respeito à formação psicológica de crianças e jovens, pois são condutas que estão na contramão do melhor interesse, visto que violam direitos assegurados no ordenamento jurídico, podendo trazer consequências permanentes no desenvolvimento da personalidade do indivíduo.

No debate sobre a Internet, por intermédio de suas redes sociais e ferramentas de transmissão de áudio e vídeo (Whatsapp, Skype, Facebook Messenger, Telegram, Zoom, dentre outras) buscou-se demonstrar que tais ferramentas já fazem parte do Judiciário, e, por óbvio, do cotidiano da população, especialmente de crianças e jovens, que praticamente crescem e desenvolvem-se em conjunto com tais tecnologias. Nesse contexto, vislumbrase que a prática da visitação virtual pode ser empregada para a aproximação entre pais e filhos afastados do convívio diário, como é o caso daquele que cumpre pena de prisão, a fim de que os laços não se rompam com a distância então imposta, inclusive visando minorar o preconceito social que o recluso carrega, visto o estigma imposto em sua figura. As instituiçóes públicas, também representadas por defensores públicos, promotores, agentes penitenciários, dentre outros envoltos no dia a dia do sistema prisional, possuem papel relevante na suavização da dita carga estigmatizadora, pois tais profissionais presenciam na prática o que implica estar na condiçáo de presidiário, e o quanto a mesma se perpetua na vida do indivíduo, mesmo após o cumprimento de sua pena. Nesse cenário, projetos e açôes inclusivas podem ser estimuladas, como é o caso da promoção de visitas virtuais.

O Judiciário, com base nas informações aqui levantadas, demonstra a relevância do princípio do melhor interesse do menor em suas decisóes, assim como o Legislativo, ao propor medidas que visem à aproximação de pais e filhos afastados do convívio diário. A Administração Pública, apesar de atender ao que estabelece o texto legal, necessita explorar novas possibilidades de interação, capazes de complementar o trabalho já realizado. Nesse contexto, o estabelecimento de visitaçóes virtuais no ambiente prisional mostra-se sim, como medida viável, capaz de trazer praticidade, comodidade, segurança e aprofundamento de laços já enfraquecidos pela distância.

Conclui-se, portanto, que a visitação virtual é uma prática viável e que, compatibilizando-se com o princípio do melhor interesse da criança e do adolescente, garante o direito 
fundamental a convivência familiar do menor com seu genitor (a) recluso (a).

Evidentemente este trabalho não visou esgotar a temática e também não adentrou à discussão dos usos das tecnologias exaustivamente indicadas, em especial no cenário de pandemia de Coronavírus que assolou o ano de 2020. É de conhecimento da autora que experiências no sentido indicado no trabalho foram feitas, entretanto, não foram aqui contempladas pois a pesquisa já encontrava-se concluída, restando portanto a necessidade de avaliar as experiências e aprofundar as discussóes.

\section{REFERÊNCIAS}

AMARAL, Érico Marcelo Hoff do; KÖHLER, Jussara Farias. A Influência da Internet nas relaçóes familiares. Repositório Digital da Universidade Federal de Santa Maria - UFSM. 2010. Disponível em: <https://repositorio.ufsm.br/bitstream/handle/1/2410/Kohler_Jussara_Farias. pdf?sequence=1>. Acesso em: 30 abr. 2019.

ATHAYDE, Aymir Ralin Pires. Informática e Justiça. 2010. Disponível em: <http://www. conteudojuridico.com.br/artigo,informatica-e-justica,28955.html>. Acesso em: 10 abr. 2019.

BAPTISTA, Silvio. Direito de visita virtual. 2010. Disponível em: <http://www.ibdfam.org. br/_img/artigos/Afetividade\%2019_12_2011.pdf>. Acesso em: 30 jul. 2018.

BARNES, Jessica; POLAK, Shely; MISHNA, Faye; SAINI, Michael. Parenting Online: An Exploration of Virtual Parenting Time in the Context of Separation and Divorce, Journal of Child Custody. 2013. Disponível em: <https://www.researchgate.net/publication/271755706_ Parenting_Online_An_Exploration_of_Virtual_Parenting_Time_in_the_Context_of_ Separation_and_Divorce>. Acesso em 04 out. 2018.

BOECHAT, Ieda Tinoco. As famílias e as tecnologias digitais: a comunicação pela articulação de vieses não antes explorados. 1. ed. Curitiba: Appris, 2017.

BRASIL. Constituiçáo (1988). Constituição da República Federativa do Brasil. Portal da Legislação Governo Federal. Disponível em:<http://www.planalto.gov.br/c civil_03/constituicao/ constituicaocompilado.htm>. Acesso em: 05 mar 2019.

Decreto no 99.710, de 21 de novembro de 1990. Convenção sobre os Direitos da Criança. Portal da Legislação Governo Federal. Disponível em:< http://www.planalto.gov.br/ ccivil_03/decreto/1990-1994/D99710.htm>. Acesso em: 06 mar. 2019.

Lei no 8.069, de 13 de julho de 1990. Estatuto da Criança e do Adolescente. Portal da Legislação Governo Federal. Disponível em:< http://www.planalto.gov.br/ccivil_03/leis/ L8069Compilado.htm>. Acesso em: 05 mar. 2019.

Lei n⿳ 10.406, de 10 de janeiro de 2002. Código Civil. Portal da Legislaçáo Governo

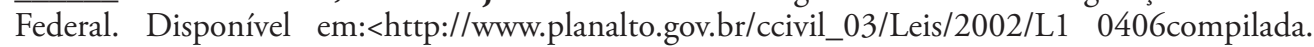
htm>. Acesso em: 09 abr. 2019.

Lei no 11.900, de 08 de janeiro de 2009. Altera dispositivos do Decreto-Lei 3.689, Código de Processo Penal. Portal da Legislação Governo Federal. Disponível em:< http://www. planalto.gov.br/ccivil_03/_Ato2007-2010/2009/Lei/L11900.htm>. Acesso em: 08 maio 2019. 
Lei no 12.318, de 26 de agosto de 2010. Lei da Alienação Parental. Portal da Legislação Governo Federal. Disponível em:< http://www.planalto.gov.br/ccivil_03/_Ato2007-2010/2010/ Lei/L12318.htm>. Acesso em: 09 abr. 2019.

Lei no 12.962, de 08 de abril de 2014. Altera a Lei no 8.069, de 13 de julho de 1990 Estatuto da Criança e do Adolescente, para assegurar a convivência da criança e do adolescente com os pais privados de liberdade. Disponível em:< http://www.planalto.gov.br/ccivil_03/_Ato20112014/2014/Lei/L12962.htm>. Acesso em: 07 maio 2019.

Lei no 13.715, de 24 de setembro de 2018. Altera o Código Penal, o Estatuto da Criança e do Adolescente e o Código Civil, dispondo hipóteses de perda do poder familiar. Portal da Legislação Governo Federal. Disponível em:< http://www.planalto.gov.br/ccivil_03/_Ato20152018/2018/Lei/L13715.htm>. Acesso em: 10 abr. 2019.

Ministério da Justiça e Segurança Pública. Conselho Nacional de Política Criminal e Penitenciária. Resoluçáo no 04, de 15 de julho de 2009. Disponível em:< http://depen.gov. $\mathrm{br} / \mathrm{DEPEN} / \mathrm{depen} / \mathrm{cnpcp} /$ resolucoes/copy2_of_Resoluo012019Sistematizaocomanexocompleta. pdf $>$. Acesso em: 09 maio 2019.

ESPÍRITO SANTO (Estado). Portaria no 142, de 26 de fevereiro de 2010. Regulamento Interno dos Centros de Detenção Provisória. Diário Oficial dos Poderes do Estado do Espírito Santo, 2010. Disponível em: < https://sejus.es.gov.br/Media/sejus/Legisla\%C3\%A7\%C3\%A3o/ Portarias/Portaria\%20n\%C2\%BA\%201582_Cadastramento\%20de\%20filhos\%20de\%20presos. pdf>. Acesso em: 09 maio 2019.

ESPÍRITO SANTO (Estado). Portaria no 1.582-S 08 de outubro de 2014. Disponível em: < https://pt.scribd.com/document/76964598/Portaria-Sejus-Regulamento-Dos-Cdps>. Acesso em: 09 maio 2019.

FARIAS, Cristiano Chaves de; ROSENVALD, Nelson. Curso de Direito Civil: Volume 6. 7. ed. São Paulo: Atlas, 2015.

GALVÁO, Danyelle da Silva. É válido realizar a audiência de custódia por videoconferência? 2016. Disponível em: < https://canalcienciascriminais.com.br/e-valido-realizar-a-audiencia-decustodia-por-videoconferencia/>. Acesso em: 10 abr. 2019.

GAZETA ONLINE. Justiça usa tecnologia para agilizar audiência e finalizar processos. 2017. Disponível em: < https://www.gazetaonline.com.br/noticias/cidades/2017/06/justica-usa-tecnologiapara-agilizar-audiencia-e-finalizar-processos-1014067770.html>. Acesso em 08 abr. 2019.

GAZETA ONLINE. Superlotaçáo em Presídios do Complexo de Xuri está em 117\%. 2019. Disponível em: <https://www.gazetaonline.com.br/opiniao/colunas/victor_hugo/2019/08/ superlotacao-em-presidios-do-complexo-de-xuri-esta-em-117-1014194895.html>. Acesso em: 19 set. 2019.

GERHARDT, Tatiana Engel; SILVEIRA, Denise Tolfo. Métodos de Pesquisa. 2009. Disponível em: <http://meiradarocha.jor.br/news/tcc/files/2017/12/Gerhardt-e-Silveira.-M\%C3\%A9todosde-Pesquisa-EAD-UFRGS.pdf>. Acesso em: 16 set. 2020.

GIL, Antônio Carlos. Como elaborar projetos de pesquisa. 4. ed. São Paulo: Atlas, 2002.

GOFFMAN, Erving. Estigma: notas sobre a manipulaçáo da identidade deteriorada. 4. ed. Rio de Janeiro: LTC, 2008. 
GOMES, Marcus Vinícius da Silva; SILVA, Antônio Dantas da Silva; TEIXEIRA FILHO, Fernando Robério Passos. Internet e as transformaçóes no direito das famílias. 2014. Disponível em: < https://jus.com.br/artigos/48913/internet-e-as-transformacoes-no-direito-das-familias>. Acesso em: 30 jul. 2018.

IBDFAM: Instituto Brasileiro de Direito de Família. STJ nega guarda compartilhada para pais que moram em cidades diferentes. 2016. Disponível em: < http://www.ibdfam.org.br/ noticias/6057/STJ+nega+guarda+compartilha>. Acesso em: 05 abr. 2019.

ISHIDA, Valter Kenji. Estatuto da Criança e do Adolescente: doutrina e jurisprudência. 16. ed. São Paulo: Atlas, 2015.

MADALENO, Ana Carolina Carpes; MADALENO, Rolf. Síndrome da Alienaçáo Parental: importância da detecção - aspectos legais e processuais. 5. ed. Rio de Janeiro: Forense, 2018.

MADALENO, Rolf. Direito de Família. 8. ed. Rio de Janeiro: Forense, 2018.

MARTINS, Verônica Pinheiro. A percepçáo das crianças sobre o pai presidiário, segundo a técnica desenho da família. 2016. Disponível em: <https://psicologado.com.br/atuacao/ psicologia-juridica/a-percepcao-das-criancas-sobre-o-pai-presidiario-segundo-a-tecnica-desenhoda-familia>. Acesso em: 04 out. 2018.

PEREIRA, Rodrigo da Cunha. Divórcio: teoria e prática. 4. ed. São Paulo: Saraiva, 2013.

ROSA, Conrado Paulino da. Curso de direito de família contemporâneo. 1. ed. Bahia: Juspodivm, 2016.

TARTUCE, Flavio. Direito Civil: direito de família. 12. ed. Rio de Janeiro: Forense, 2017. 